\title{
Methods of Gathering Data for Research Purpose and Applications Using IJSER Acceptance Rate of Monthly Paper Publication (March 2012 Edition-May 2013 Edition)
}

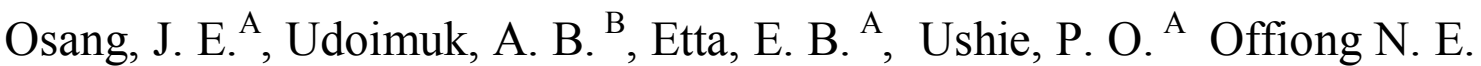 \\ A. Department Of Physics, Cross River University Of Technology Calabar, Nigeria \\ B. Department Of Physics University Of Calabar ,Calabar
}

\begin{abstract}
A good number of scientist or researchers find it very difficult in carrying out their research work successfully due to lack of good knowledge of data collection method and application. Data is referred to as a collection of facts, such as values or measurements, observation or even just descriptions of things. Various ways are used for data collection in research work or designs depending on the research being done by the researcher. This study focuses on the Acceptance rate of monthly IJSER paper publication (March 2012 Edition-May 2013 Edition).

Simple descriptive analysis was used. The result shows that Quantitative analysis is considered to be objective, without any human bias attached to it, because it depends on the comparison of numbers according to mathematical computations. While Analysis of qualitative data is generally accomplished by methods more subjective, dependent on people's opinions, knowledge, assumptions, and inferences (and therefore biases), than that of quantitative data.
\end{abstract}

Key words: Data, ijser"s Acceptance rate, qualitative and quantitative approach, Observation, Survey, Interview, Experiment, etc.

\section{MEANING OF DATA:}

\section{Introduction}

The word data is the plural form of datum. It has been defined in several ways according to different persons in their area of specialisation and occasion. In this study, data is referred to as a collection of facts, such as values or measurements, observation or even just descriptions of things. Data collection is very important in any type of research study. Inaccurate data collection causes great impact on the result of a study and ultimately lead to invalid results which must be avoided (Burchfield,1996), (Tim ,1997), (Matt, 2001).

\section{CLASSIFICATION OF DATA}

Data can be classified into Primary and Secondary Data

Primary Data: primary data are those that you have collected yourself or the data collected at source or the data originally collected by individuals, focus groups, and a panel of respondents specifically set up by the researcher whose opinions may be sought on specific issues from time to time (Matt, 2001), (Afonja, 2001).

\section{Advantage Of Primary Data}

$>$ More accurate information can be gotten

$>$ It is less expensive

$>$ It is current (the information may to the prevailing situation).

\section{Disadvantages Of Primary Data}

$>$ It is time - consuming/energy

$>$ More difficult to collect

2. Secondary Data: a secondary data research project involves the gathering and/or use of existing data for which they were originally collected, for example, computerized database, company records or archives, government publications, industry analysis offered by the media, information system and computerized or mathematical models of environmental processes and so on (Tim ,1997), (Matt, 2001).

\section{Advantages Of Secondary Data \\ $>$ less expensive \\ $>$ more easier to collect than primary data \\ $>$ cost effective}

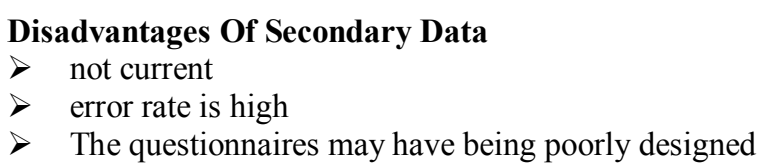




\section{DIFFERENT KINDS OF DATA COLLECTION}

There are two kinds of data, although not all evaluations will necessarily include both. These are:-

$>\quad$ Quantitative data and

$>\quad$ Qualitative data

\section{Quantitative data}

Quantitative data is data that is mainly numbers. It refer to the information that is collected as, or can be translated into, numbers, which can then be displayed and analyzed mathematically. Quantitative data are Structured and Unstructured in nature .Structured data is organised, while unstructured data is relatively disorganised. .Structured data can be produced by closed questions, unstructured data can be produced by open questions. (Checkland et al 1998), (Matt, 2001), (Burchfield, 1996), (Anyanwu, 2002).

\section{Closed questions}

- Closed questions can make analysis of data relatively easy, but their responses are restricted.

\section{Open questions}

In the case of an open question, their responses are not restricted. This will produce almost completely unstructured data. Although the open question produces data that is difficult to organise and code, it allows subjects to respond freely and express shades of opinion rather than forcing them to have precoded opinions. As discussed, quantitative data are typically collected directly as numbers( Afonja, 2001),( Anyanwu, 2002). Some examples include:

- The frequency (rate, duration) of specific behaviours or conditions

- Test scores (e.g., scores/levels of knowledge, skill, etc.)

- Survey results (e.g., reported behaviour, or outcomes to environmental conditions; ratings of satisfaction, stress, etc.)

- Numbers or percentages of people with certain characteristics in a population (diagnosed with diabetes, unemployed, Spanish-speaking, under age 14, grade of school completed, etc.) (Burchfield, 1996), (Afonja, 2001).

Quantitative data is usually subjected to statistical procedures such as calculating the mean or average number of times an event or behaviour occurs (per day, month, year). These operations, because numbers are "hard data" and not interpretation, can give definitive, or nearly definitive, answers to different questions. Various kinds of quantitative analysis can indicate changes in a dependent variable related to - frequency, duration, timing (when particular things happen), intensity, level, etc. They can allow you to compare those changes to one another, to changes in another variable, or to changes in another population. They might be able to tell you, at a particular degree of reliability, whether those changes are likely to have been caused by your intervention or program, or by another factor, known or unknown. And they can identify relationships among different variables, which may or may not mean that one causes another (Burchfield, 1996), (Afonja, 2001), (Anyanwu, 2002).

\section{Qualitative data}

Qualitative data is data that is mainly words, sounds or Images. Unlike numbers or "hard data", qualitative information tends to be "soft," meaning it can't always be reduced to something definite. That is in some ways a weakness, but it's also a strength. A number may tell you how well a student did on a test; the look on her face after seeing her grade, however, may tell you even more about the effect of that result on her. That look can't be translated to a number, nor can a teacher's knowledge of that student's history, progress, and experience, all of which go into the teacher's interpretation of that look. And that interpretation may be far more valuable in helping that student succeed than knowing her grade or numerical score on the test (Matt, 2001), ( Afonja, 2001), (Burchfield, 1996).

As explained above, qualitative data can sometimes be changed into numbers, usually by counting the number of times specific things occur in the course of observations or interviews, or by assigning numbers or ratings to dimensions (e.g., importance, satisfaction, ease of use).

The challenges of translating qualitative data into quantitative data have to do with the human factor. Qualitative data can sometimes tell you things that quantitative data can't. It may reveal why certain methods are working or not working, whether part of what you're doing conflicts with participants' culture, what participants see as important, etc. It may also show you patterns in behaviour, physical or social environment, or other factors that the numbers in your quantitative data don't, and occasionally even identify variables that researchers weren't aware of. It is often helpful to collect both quantitative and qualitative information (Tim, 1997), (Anyanwu, 2002).

Quantitative analysis is considered to be objective, without any human bias attached to it, because it depends on the comparison of numbers according to mathematical computations. Analysis of qualitative data is generally accomplished by methods more subjective, dependent on people's opinions, knowledge, assumptions, and inferences (and therefore biases), than that of quantitative data. The identification of patterns, the interpretation of people's statements or other communication, the spotting of trends, all of these can be influenced by the way the researcher sees the world. Quantitative analysis is influenced by a number of subjective factors as well. What the researcher chooses to measure, the accuracy of the observations, and the way the research is structured to ask only particular questions can all influence the results, as can the researcher's understanding and interpretation of the subsequent analyses (Afonja, 2001). 


\section{TYPES OF DATA}

We can identify the following types data

Continuous Data: Data that is measured on an interval scale such as length or weight. It does not have a precise value. It depends on the required degree of accuracy depending on the measuring devices used.

$>\quad$ Discrete Data: Data that that are obtained by counting, and are measured precisely.

$>\quad$ Ordinal Data: Data that is given a numerical value and can only be placed in a suitable category(Burchfield,1996).

\section{WAYS OF COLLECTING DATA}

Data can be collected in a variety of ways, in different settings, and from different sources. Data Collection methods include interviews, questionnaires, experiment, observation, sample survey, census, etc that are either personally administered, send through the mail, or electronically administered; observations of individuals and events with or without videotaping or audio recording and a variety of other motivational techniques such as projective tests (Tim, 1997), (Burchfield,1996).

\section{Interviews method}

An interview is a series of questions a researcher addresses personally to respondents. An interview may be structured (where you ask clearly defined questions) or unstructured, where you allow some of your questioning to be led by the responses of the interviewee. Especially when using unstructured interviews,

using a tape recorder can be a good idea, if it does not affect the relationship with the person being interviewed. Interviewing method is sub-divided into the following: Face-to-face interviews, Telephone interviews, etc (Checkland et al 1998).

\section{Face-to-face interviews}

This type provides rich data, offer the opportunity to establish rapport with the interviewees, and help to explore and understand complex issues. many ideas that are ordinarily difficult to articulate can also be surfaced and discussed during such interviews. On the negative side, face-to-face interviews have the potential for introducing interviewer bias and can be expensive if a big sample of subjects is to be personally interviewed (Tim, 1997), (Erricker, 1971), (Burchfield,1996), (Matt, 2001).

\section{Telephone interviews}

This help to contact subjects dispersed over various geographic regions and obtain responses from them immediately on contact. This is an efficient way of collecting data when one has specific questions to ask, needs the responses quickly, and has the sample spread over a wide geographic area. On the negative side, the interviewer cannot observe the nonverbal responses of the respondents, and the interviewee can block a call. Personally administering questionnaires to groups of individuals (Tim, 1997).

\section{Advantage Of Interview Method}

$>$ To get full range and depth of information.

$>$ Misunderstandings are avoided as far as humanly possible by carefully defined terms

Sensitive questions can be carefully squeezed in between other less sensitive ones by the interviewer.

$>$ Develops relationship with client.

$>$ Encouraging response more likely as people are most willing to respond on person to person chat.

$>$ Status and educational level of the respondents will enumerator may use.

$>$ Can be flexible with clients(Tim, 1997), (Erricker, 1971).

\section{Disadvantage of Interview Method}

$>$ Can take much time.

$>$ Can be costly.

$>$ Personal prejudices, biases and other ill feelings are maximum under this method especially when issues of what to wear, what to say, how to say it etc are not stressed to the enumerator.

$>$ Const implication in terms of area to cover, persons to interview and other resources is usually high.

$>$ Thorough training and supervision of the interviewers involves well carefully planned and executed process that will reduce incorrect information.

$>$ Can be hard to analysis and compare.

$>$ Respondents may give out their confidential information in the presence of interviewer. Example is whether they have an AIDS/HIV patient in his/her household. Most respondents may answer correctly if mail questionnaire is used.

$>$ Interviewer can bias clients responses (Anyanwu, 2002), (Erricker, 1971).

\section{Questionnaire method}

A questionnaire is a series of written questions a researcher supplies to subjects, requesting their response. Usually the questionnaire is self-administered in that it is posted to the subjects, asking them to complete it and post it 
back. The way you will be analysing the data may influence the layout of the questionnaire. For example, closed questions provide boxes for the respondent to tick(giving easily coded information), whereas an open question provides or a box for the respondent to write answers in (giving more freedom of information, but more difficulty coding) (Checkland et al 1998), (Burchfield,1996), ( Anyanwu, 2002).

\section{Traps to avoid when Interviews or when writing Questionnaires}

The double question: For example: Do you walk to school or carry your lunch?'

The wording of such questions makes them difficult or impossible to answer accurately. Some may contain two or more unrelated parts. Some may contain contradictory parts, the answers to which may be different (Anyanwu, 2002), (Tim, 1997)..

The wrong choice question: Example: "Is your hair yellow, purple, green or blue?" needs to have an alternative. Common sense is often not enough to ensure you give respondents enough choice, for what may appear bizarre or unthinkable behaviour to you (and therefore ignored in your questionnaire) may be(Burchfield,1996);

The 'fuzzy word' question: Example: 'Should middle-aged people live it up?' has two problems. 'Middle-aged' does not mean the same age group to everyone, and 'living it up' can mean anything from wearing red to keeping a harem. Fuzzy words can creep into almost any question: 'Do you attend dances frequently?' (or 'rarely' or 'occasionally' or' often') will give meaningless answers ( Burchfield, 1996).

The 'cover the world' question: Example: 'What do you think of the President? could refer to the man or woman personally, or to how he/she is carrying out the role of president of a company or a nation. What is the neighbourhood like?' is useful in some interviews, but if you know what aspect of the neighbourhood interests you ask specifically about that (Erricker,1971), (Matt, 2001).,

Jargon questions: Jargon questions should be avoided. Example 'Do you feel that your

husband has a self actualising autonomous personality structure?' is an affront to the respondent and also to the English language. Also, being careful about words that have one meaning to the professionalism your field and another, or none, to the public. 'Culture, 'personality,' 'role,' or 'institution,' cannot be treated as if all respondents shared a common understanding of the professional meaning you intended. More generally, the language and style of the questionnaire must be comfortable' to the respondent. 'Writing down is insulting, and using dialect or 'in' words to reach a group of which you are obviously not a member is usually inappropriate (Erricker, 1971).

The 'kitchen sink' question: Example 'Please list all the places you have worked in the past five years, the type of work done and salary received, and why you left.' To save

Leading questions: Example 'Why are you happy here in Newtown?' or 'Why do you think the community looks up to doctors?' gives the respondent little opening to say he/she is miserable in Newtown and thinks that most of the people in the community feel helps to establish rapport with the respondents while introducing the survey, provide clarifications sought by the respondents on the spot, and collect the questionnaires immediately after they are completed. On the negative side, administering questionnaires personally is expensive, especially if the sample is geographically dispersed (Burchfield, 1996).

Mailed questionnaires are disadvantageous when responses to many questions have to be obtained from a sample that is geographically dispersed and when conducting telephone interviews to obtain the same data is difficult, more expensive, or not feasible. On the negative side, mailed questionnaires usually have a low response rate and one cannot be sure if the data obtained are biased because the no respondents may be different from those who did respond (Matt, 2001).

It is important to ask questions in a way that would ensure the least bias in the response. For example, "Tell me how you experience your job" is a better question than saying, "Boy, the work you do must be really boring; let me hear how you experience it." the later question is "loaded" in terms of the interviewer's own perceptions of the job. A loaded question might influence the types of answers the responded gives. Bias could be also introduced by emphasizing certain words, by tone and voice inflections, and through inappropriate suggestions (Anyanwu, 2002).

Because almost all data-collection methods have some biases associated with them, collecting data through multimethods and from multi-sources lends rigor to research. For instance, if the responses collected through interviews, questionnaires, and observations are strongly correlated with each other, then we will have more confidence about the goodness of the data that are being collected. If there are discrepancies in how the respondent answers the same questions when interviewed, as opposed to how he/she answers the question in a questionnaire, then we would be inclined to discard the data and being biased (Burchfield,1996).

\section{Advantage of Questionnaire Method}

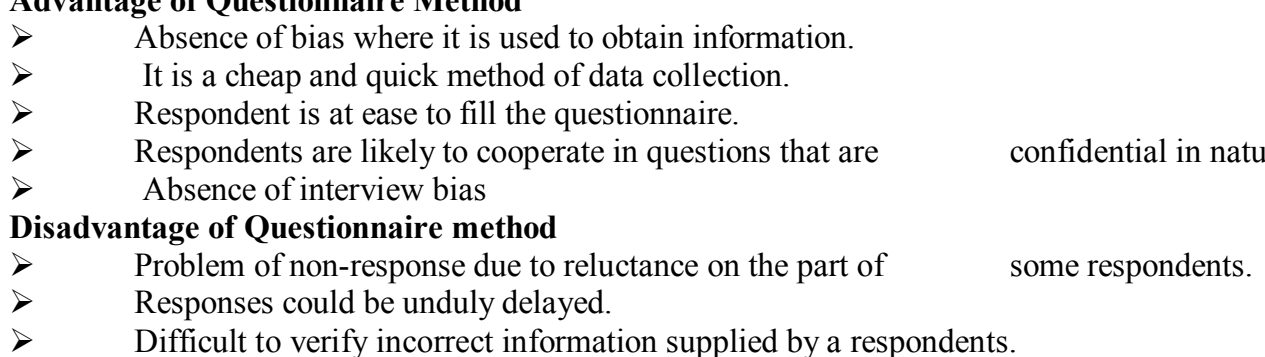


Wrong person may complete the from allowing errors to creep into the survey.

$>\quad$ Absence of enumerators to explain any intricacy in the questions.

$>\quad$ Poor method where a spontaneous answer is required.

\section{Observational study method}

Like experiments, observational studies attempt to understand cause - and effect relationships, However, unlike experiments, the researcher is not able to control

i. How subject are assigned to groups and or

ii. Which treatments each group receives (Matt, 2001).

Observational studies help to comprehend complex issues through direct observation (either as a participant- or a nonparticipant-observer) and then, if possible, asking questions to seek clarifications on certain issues. On the negative side, they are expensive since long periods of observation are required, and observer bias may well be present in the data. (Burchfield,1996), (Matt, 2001).

\section{Advantage of Observation method}

$>\quad$ The researcher can adapt to events as they occur.

$>\quad$ Given normal conditions, complete set of data are usually

$>\quad$ Suitable in studying small fraction of the subjects that the

obtained.

Advantage of recording events as they occur.

$>\quad$ Reduction of bias is evident.

$>\quad$ Reliable and objective data are obtained.

Useful in studying small communities, institutions and laboratory work.

It help the researcher to view operations of program as they actually occurring. (Burchfield,1996).

Disadvantage of Observation method

researcher is interested on.

$>\quad$ Can be difficult to interpret seen behaviours.

$>\quad$ Inability to observe motivation and plans.

$>\quad$ Can influence behaviours of program participants.

Hard to observe events of short-term duration.

$>\quad$ Can be expensive.

$>\quad$ Inability to keep the observation secret to the respondent.

$>\quad$ Can be complex to categorize observations. (Burchfield,1996).

\section{Experimental method}

Experimental method may be used in scientific research as this is preferred to other ways of collecting data in the science and engineering perspective. An experiment is a controlled study in which the researcher attempts to understand cause and effect relationships. The study is "controlled" In the sense that the researcher controls.

i. $\quad$ How subjects are assigned to groups and

ii. Which treatments each group receives (Matt, 2001).

\section{ADVANTAGES OF EXPERIMENTAL METHOD}

1. Absent of bias where it is use to obtained information or

2. It is quick in data collection

3. Data are more reliable and objective.

4. It is the best way for data collection in Scientific research

5. It cost consuming

\section{DISADVANTAGES OF EXPERIMENTAL METHOD}

1. If the set-up is wrong, data will be incorrect.

2. It is time consuming

3. It need only expert in the field. (Matt, 2001).

\section{SURVEYS METHOD}

This consists of finding facts in particular fields of inquiry. We have three important surveys in which data collected are of a statistical nature. They are social survey and public opinion polls (Matt, 2001), (Erricker, 1971).

a. Social Survey: is a survey meant to provide information for other Government Departments so that they could carry out their duties more efficiently. Many bodies do conduct social surveys - as, for example, the universities but the most important is the social survey department of the government like that of Federal of Statistics (FOS) in Nigeria (which is now called Federal Bureaus of Statistics) (Burchfield,1996), (Erricker, 1971).

b. market Research: This involves the use of surveys, tests, and statistical studies to analyze consumer trends and to forecast the size and location of markets for specific products or services. The social sciences are increasingly utilized in customer research. Psychology and sociology, for example, by providing clues ton people a activities, circumstances, wants, desires, and general motivation, are keys to understanding the various behavioural pattern of consumers. (Erricker, 1971). 
c. Public Opinion Polls: this is a technique that measures the attitude, perspectives, and preferences of a population towards events, circumstance and issues of mutual interest. Both random and quota sampling are used.

\section{Census method}

A Census is a study that obtains data from every member of a population, In most studies, a census is not practical, because of the cost and/ or time required (Erricker, 1971).

\section{DISADVANTAGE OF CENSUS}

Census is very elaborate matter involving planning, pilot and complexities.

$>\quad$ Huge sums of money are usually sunk into planning and

$>\quad$ Huge resources (human and material) are required to cover respondents.

$>\quad$ Interviewers (enumerators). Frequently have problems of

$>\quad$ Some remote area is inaccessible.

$>\quad$ Lack of interest by some members of the population who by inclination may resist to be enumerated.

$>\quad$ Delay in detailed editing and analysis of the returns

This takes some time to be understood (Erricker, 1971).

\section{CASE STUDIES METHOD}

It helps the researcher to fully understand or depict clients experiences in a program, and conduct comprehensive examination through cross comparisons of cases.

\section{ADVANTAGE}

$>$ Fully depicts client's experience in program input, process and results.

$>$ Powerful means to portray program to outsiders.

\section{CHANLLAGES}

$>$ Usually quite time consuming to collect, organize and describe.

$>$ Represents depth of information rather than breadth.

\section{MATERIALS AND METHODS}

Data source

The data for the acceptance rate of monthly IJSER paper publication (march 2012 edition-may 2013 edition) was extracted from the international journal of scientific \& engineering research (IJSER). Descriptive method of analyses was employed showing:- multiple bar chart of acceptance and publication rate of monthly IJSER paper publication (march 2012 edition-may 2013 edition).

\section{RESULT}

Table 1: Acceptance rate of monthly ijser paper publication (March 2012 Edition-May 2013 Edition)

\begin{tabular}{|c|c|c|c|c|c|c|}
\hline S. S & $\begin{array}{l}\text { AME OF } \\
\text { AMERAL } \\
\text { OUR }\end{array}$ & E DITION DATE & $\begin{array}{l}\text { TOTAL NO. OF } \\
\text { PAPER FOR } \\
\text { REVIEW }\end{array}$ & $\begin{array}{c}\text { TOTAL NO. OF } \\
\text { PAPER } \\
\text { ACCEPTED } \\
\text { FOR } \\
\text { PUBLICATION }\end{array}$ & $\begin{array}{c}\text { TOTAL NO. OF } \\
\text { PAPER } \\
\text { REGISTERED } \\
\text { FOR } \\
\text { PUBLICATION }\end{array}$ & $\begin{array}{c}\text { ACCEPTANCE } \\
\text { RATE } \%\end{array}$ \\
\hline 1 & IJSER.ORG & $\begin{array}{l}\text { MARCH, } 2012 \\
\text { EDITION }\end{array}$ & 700 & 98 & 90 & 14.1 \\
\hline 2 & IJSER.ORG & $\begin{array}{l}\text { APRIL, } 2012 \\
\text { EDITION }\end{array}$ & 712 & 150 & 143 & 21 \\
\hline 3 & IJSER.ORG & $\begin{array}{l}\text { MAY, 2012 } \\
\text { EDITION }\end{array}$ & 924 & 230 & 210 & 24.8 \\
\hline 4 & IJSER.ORG & $\begin{array}{l}\text { JUNE, 2012 } \\
\text { EDITION }\end{array}$ & 889 & 220 & 197 & 24.77 \\
\hline 5 & IJSER.ORG & $\begin{array}{l}\text { JULY, } 2012 \\
\text { EDITION }\end{array}$ & 911 & 170 & 162 & 18.6 \\
\hline 6 & IJSER.ORG & $\begin{array}{l}\text { AUGUST, } 2012 \\
\text { EDITION }\end{array}$ & 745 & 185 & 170 & 24.8 \\
\hline 7 & IJSER.ORG & $\begin{array}{l}\text { SEPTEMBER, } \\
2012 \text { EDITION }\end{array}$ & 801 & 134 & 123 & 15.35 \\
\hline 8 & IJSER.ORG & $\begin{array}{l}\text { OCTOBER, } 2012 \\
\text { EDITION }\end{array}$ & 980 & 212 & 198 & 21.63 \\
\hline 9 & IJSER.ORG & $\begin{array}{l}\text { NOVEMBER, } \\
2012 \text { EDITION }\end{array}$ & 860 & 187 & 140 & 21.7 \\
\hline 10 & IJSER.ORG & $\begin{array}{l}\text { DECEMBER, } \\
2012 \text { EDITION }\end{array}$ & 910 & 167 & 157 & 18.35 \\
\hline 11 & IJSER.ORG & $\begin{array}{l}\text { JANUARY, } 2013 \\
\text { EDITION }\end{array}$ & 892 & 172 & 160 & 19.28 \\
\hline 12 & IJSER.ORG & $\begin{array}{l}\text { FEBRUARY, } \\
2013 \text { EDITION }\end{array}$ & 912 & 140 & 133 & 15.35 \\
\hline 13 & IJSER.ORG & $\begin{array}{l}\text { MARCH, } 2013 \\
\text { EDITION }\end{array}$ & 872 & 142 & 130 & 16.28 \\
\hline 14 & IJSER.ORG & $\begin{array}{l}\text { APRIL, } 2013 \\
\text { EDITION }\end{array}$ & 1400 & 240 & 205 & 17.14 \\
\hline 15 & IJSER.ORG & $\begin{array}{l}\text { MAY, } 2013 \\
\text { EDITION }\end{array}$ & 1520 & 310 & 285 & 20.39 \\
\hline
\end{tabular}




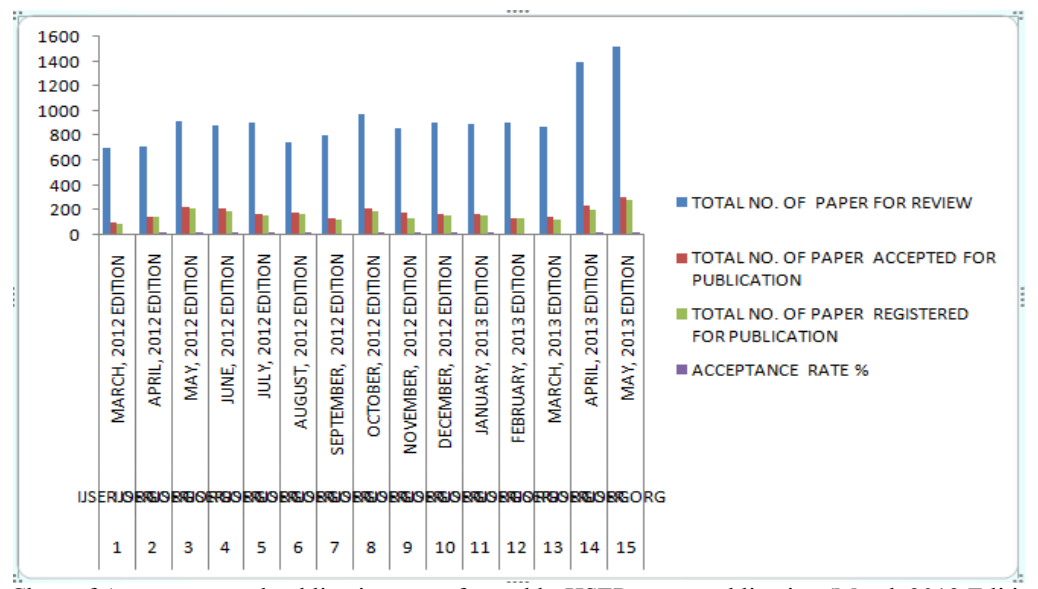

Fig: MULTIPLE Bar-Chart of Acceptance and publication rate of monthly IJSER paper publication (March 2012 Edition-May 2013 Edition)

\section{DISCUSSION OF RESULT}

Base on the result, the analysis on the methods of gathering data for research purpose and applications, using IJSER acceptance rate of monthly paper publication (march 2012 edition-may 2013 edition), shows that total number of papers sent for review is very high, table 1, fig. 1: indicating a high intention rate of the researchers in research work. Main while, total number of paper accepted and register for publication is very low, table 1 , fig. 1; indicating that, the number of good quality paper sent is low. This is probably as a result of lack of good knowledge of data collection method and application.

\section{Summary and Conclusion}

Conclusively, the heart of evaluation in every research work, is to gather information about the program or intervention in evaluating and analyzing it, to determine what it tells about the research. The effectiveness of what the researcher is doing, as well as about how he/she can maintain and improve the situation.

Hence, the quality and success of a research work depends the on the knowledge of data collection method and application. Base on the result, Quantitative analysis is considered to be objective, without any human bias attached to it, because it depends on the comparison of numbers according to mathematical computations. While Analysis of qualitative data is generally accomplished by methods more subjective, dependent on people's opinions, knowledge, assumptions, and inferences (and therefore biases), than that of quantitative data.

After the data have been collected and filtered from a representative sample of the population, the next step is to analyze the data so that the research hypotheses can be tested. These steps help to prepare the data for analysis, ensuring that, the data obtained are reasonably good and allow the results to be meaningfully interpreted. These four steps are:

(1) Getting data ready for analysis,

(2) Getting a feel/ filtering the data,

(3) Testing the goodness of data,

(4) Testing the hypotheses.

(5) Etc.

\section{References}

[1]. Collecting and analyzing data. http://ctb.ku.edu. Retrieved 09/06/2013 01:59pm

[2]. Data collection method.www.twely. Co. uk/ data + collection + method retrieved 09/06/2013;03:30pm.

[3]. Data collection methods; http//people.uwec.edu Retrieved 9/06/013: 01:50pm.

[4]. Data collection, compilation and dissemination http://wwww.tffs.org retrieved 09/006/2013;02:50pm.

[5]. Data collection.http:// psychology.about com retrieved 09/06/2013,02:30pm.

[6]. Data winners; https://www.datawinners. Retrieved 09/06/2013 01:47pm.

[7]. Data, its collection, and related issues http://www.wwetc.com.retrieved 09/06/2013 021:10pm

[8]. Evaluation 4-H youth development programs http:// 4h. uwex. Edu.retrieved 09/06/2013;02:35pm.

[9]. Method of data collection.wwwfreapp. Com retrieved 09/06/2013;03:40pm.

[10]. Methods of collecting data interviews and questionnaires in practice.http://www.eghid.edu. Retrieved 02:05pm, 09/06/2013.

[11]. Methods of data collection digstar.com/method + of + data + collection. Retrieved $09 / 06 / 2013 ; 03: 02 \mathrm{pm}$

[12]. Methods of data collection.http://www.digstar.com retrieved 09/06/2013: 02:55pm.

[13]. Overview of basic methods to collect information http:// management help. Retrieved 09/06/2013;02;40pm

[14]. Afonja, B. (2001). Introduction statistics Evans Brothers (Nig) publishers Ltd Ibadan- Nigeria.

[15]. Anyanwu, S. A. C. (2002). Descriptive statistics for Business science and Engineering students spring field publishers Owerri-Nigeria.

[16]. Erricker, B. C. (1971). Advanced general Statistics Hodder and stonghton London.

[17]. Hines, W. W. et al (2003). Probability and statistics in Engineering John Wiley and Sons New York.

[18]. Onyegam, S.O. (2003). Essentials of Business statistics Pen Paper Publishers Aba -Nigeria.

[19]. R.W. Burchfield, ed. (1996). "data". Fowler's Modern English Usage (3rd ed.). Oxford: Clarendon Press. pp. 197-198. ISBN 0-19-8691262: Retrieved 09/06/2013, 02:30pm

[20]. Tim Johns (1997). "Data: singular or plural?". "...in educated everyday usage as represented by The Guardian newspaper, it is nowadays most often used as a singular." retrieved 09/06/2013, 03:30pm

[21]. Matt Dye (2001). "Writing Reports". University of Bristol retrieved 11/06/2013, 01:20pm.

[22]. P. Checkland and S. Holwell (1998). Information, Systems, and Information Systems: Making Sense of the Field. Chichester, West Sussex: John Wiley \& Sons. pp. 86-89. ISBN 0-471-95820-4. retrieved 10/06/2013, 03:37am 